\title{
APPLICATION OF ENERGY HARVESTING SYSTEM IN HYBRID AUTOMOBILES
}

\author{
Nitij Vashisht ${ }^{1}$, Radhika Ramtri ${ }^{2}$, Prince Oberoi $^{3}$, Kusum Grewal Dangi ${ }^{4}$ \\ ${ }^{1,2,3,4}$ Department of Electronics and Communication Engineering, The NorthCap University, Gurgaon
}

\begin{abstract}
This paper presents the concept of hybrid automobile using energy harvesting system. In this work solar energy, wind energy, ambient noise and suspension energy harvesting systems have been used. The system hardware prototype has been made and its efficiency has been calculated. The proposed system can prove to be a trend changing and very efficient in this time of depleting non renewable resources.
\end{abstract}

Keywords: Renewable Resources, Non-Renewable Resources, Energy Harvesting System, Hybrid Automobile.

$* * *$

\section{INTRODUCTION}

As the non renewable energy sources are depleting, a need of using renewable energy sources as primary fuel source is being felt. The device which uses the renewable energy sources like solar and wind; and manmade sources like noise, speed breakers etc; to generate and store energy is known as energy harvesting systems(EHS). Tremendous work is going on EHS. EHS has got vast applications ranging from wearable devices to automobiles. The EHS can be of two types simple EHS and hybrid EHS. Simple EHS uses only one energy source while hybrid EHS uses multiple methods of energy source like combination of Solar and ambient temperature harvester to power devices in the area where sunlight is in abundance. The various renewable energy sources are: Solar, Wind and Water. Manmade energy source are like Thermal Noise, RF noise, suspension system. The combination of the energy sources can be used based on the type of geography of the application device. For example, in Africa, solar energy is in abundance; coastal area can use tidal energy source; "chakarwaat" area can use wind energy for power generation; the metropolitan cities can make best use of the RF noise created by the towers and noise created by vehicular traffic whereas the non planar areas where there are a lot of speed breakers, suspensions can be used as a good energy harvesting approach.

In our proposed system solar, ambient noise, wind and suspension sources are used as four parameters to generate the energy for the automobile battery charging application.

\section{ENERGY HARVESTING SYSTEMS}

There are various existing EHS. In this paper we have discussed four major forms of energy viz solar energy, wind energy, energy from ambient noise and suspension energy. India, as a tropical country has ample amount of sunlight, wind near the coastal areas. It also has a lot of noise due to bustling metropolitan cities and road bumps, which all add up to huge potential for the use of the following energy resources. A detailed view of such system is mention in table1.
Table 1. Existing Energy Harvesting System

\begin{tabular}{|l|l|l|}
\hline $\begin{array}{l}\text { Sr. } \\
\text { no. }\end{array}$ & EHS & Application \\
\hline 1 & Solar & $\begin{array}{l}\text { Solar water heater, solar inverter } \\
{[1], \text { Fresnel reflector[1] }}\end{array}$ \\
\hline 2 & Wind & $\begin{array}{l}\text { Water pumping [4],Stand alone system } \\
\text { for houses[4],Power system for schools } \\
\text { and hospitals[4] }\end{array}$ \\
\hline 3 & $\begin{array}{l}\text { Ambient } \\
\text { Noise }\end{array}$ & Sonar [5] \\
\hline 4 & Pressure & Pressure exchanger[6] \\
\hline
\end{tabular}

\section{A. Solar Energy Harvesting System}

Solar energy has a wide market. Over the years the market for this segment has been ever increasing specially the market of Photo Voltaic (PV) systems. Although the cost of solar technologies is high vis a vis other sources of energy, the cost has been decreasing in the recent past years and shows a great potential for more decrease in the years to come[1]. It has various benefits associated with it like solar energy is a clean and renewable source of energy, available in ample amount; solar resources are available all around the globe. It is environment friendly.

The solar energy is produced using Solar Photovoltaic (PV) method. This method states that Sunlight constituting of tiny energy packets called photons and each solar cell is fabricated with a negative and a positive layer, thus creating an electric field (similar to batteries). As the photons are absorbed in the cell, the energy generated causes the electrons to get free and they move downward, and move out through the wires, hence generating electricity. The electric energy produced is directly proportional to the sun light availability. 


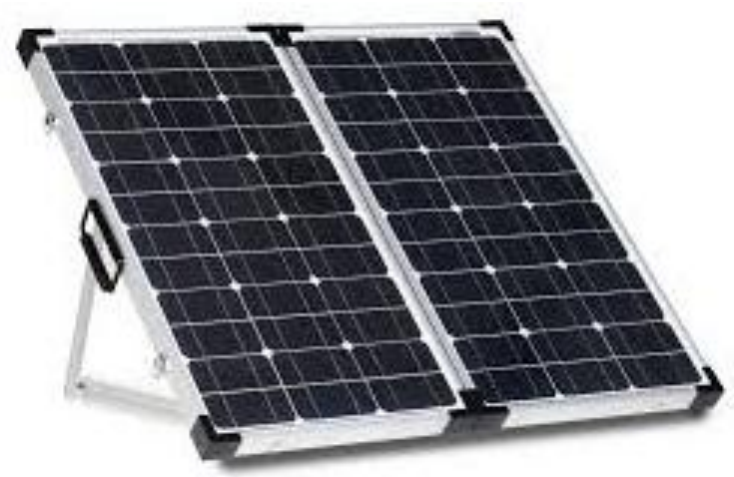

Figure 1. Solar panel

\section{B. Wind Energy}

India has great potential for harvesting wind energy. Wind in India is dictated by the strong south west summer wind in May which when cools travels towards land and when weak, moves to north east monsoon. The winds are strong in the entire peninsula from August, especially the coastlines.

The system consists of blades, attached with a controller and a high speed shaft, connected to an axel which is connected to a rotor which is in turn connected to a dynamo which converts the incoming wind energy into electrical energy for use.

Any given object or fluid in motion has kinetic energy because of the velocity it possesses.

For example, wind which is a mass of air in motion possesses kinetic energy. More the speed of the wind, more the kinetic energy. The kinetic energy of a mass of wind can be calculated as follows.

$E=m v^{2} / 2$

Where

$\mathrm{E}$ is the kinetic energy in Joules.

$\mathrm{M}$ is the mass of air in kilograms.

$\mathrm{V}$ is the velocity of the air in meters per second.

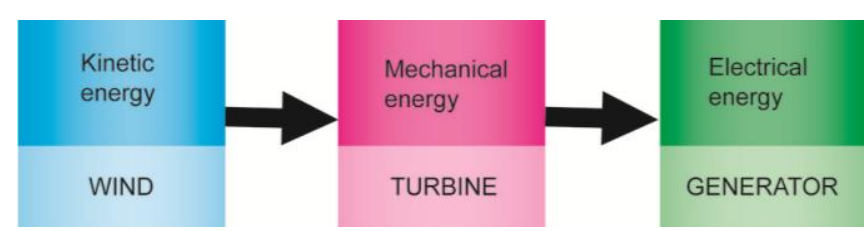

Figure 2. wind energy

\section{Suspension energy}

Regenerative shock absorber is another kind of suspension system which converts intermittent linear motion and vibrations into any form of energy which is useful, say electric energy.

Common shock absorber simply dissipates energy as heat. Owing to the fact that India is a developing country, having its own challenges like pot holed roads and bumps. This can be used as an advantage and converted into electrical energy for driving a vehicle. The following is a diagram to illustrate the same.

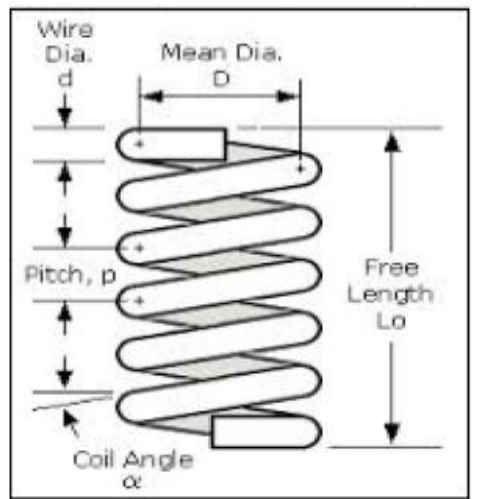

Figure 3. suspension energy

In the following project we have used suspension energy by using rack and pinion method which is less costly than a hydraulic unit. It is more economical and better in terms of its energy output.

The parts include.

1. A suspension unit

2. A rack and pinion arrangement

3. Dynamo

\section{Ambient Noise harvester}

India is the second largest populated country after China. The increasing population is both a liability and a boon. The growing population produces a lot of noise from honking of the cars to the voices. This can be used to our advantage by converting noise into electrical energy. Noise energy is converted into a useful form of energy by using a transducer. This is done by using a transducer that converts vibrations caused by sound or noise into electrical energy. In this project, a speaker and a transformer are used to convert noise produced by a vehicle into electrical energy. These vibrations can be converted into electrical energy by using the principle of electromagnetic induction. The received signal is amplified by using a step up transformer.

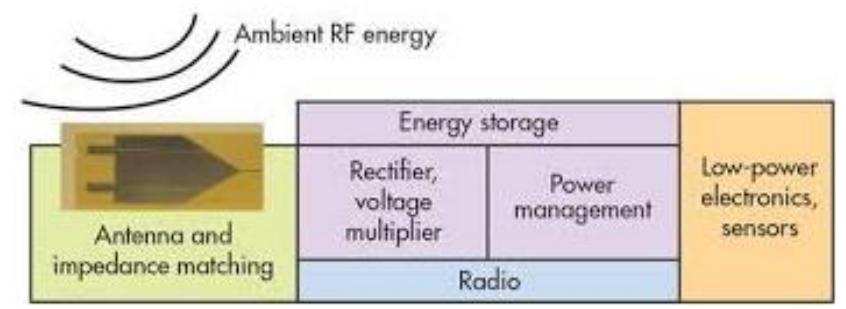

Figure 4. Ambient noise harvester

\section{SYSTEM ARCHITECTURE}

In this paper, we have introduced a hybrid vehicle using various EHS as stated above. The prototype as shown in figure 5 and figure 6 consists of a hard board base, mounted on $5 \mathrm{~cm}$ diameter rubber wheels, which are connected via screws and would be powered by the motor. An on/off switch has been installed to power the motor. Another switch is installed to decide the direction of the vehicle. A 7 watt Solar panel is put up on incline, to harvest incoming solar energy. The solar panel is installed on the wooden plate, connected to three rechargeable batteries, 4 volts each. 


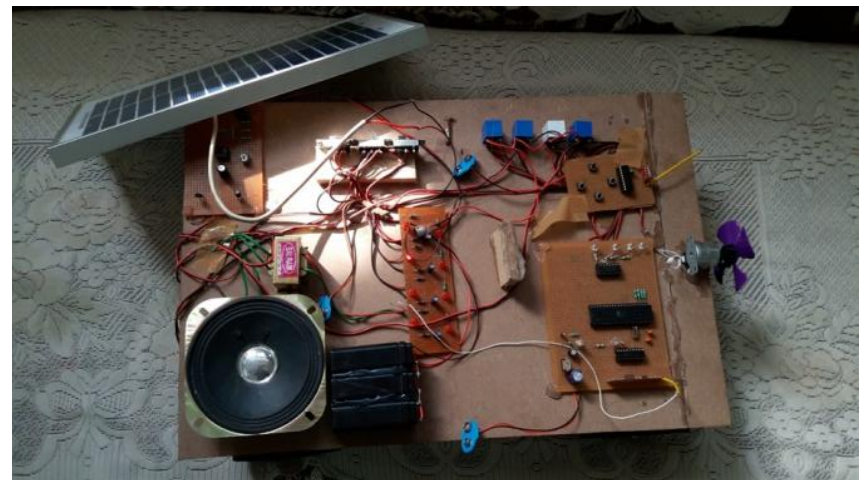

Figure 5. Prototype

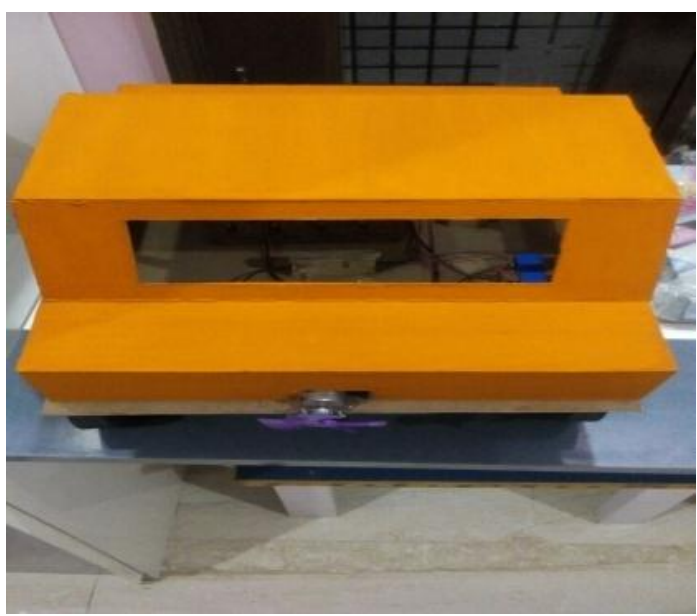

Figure 6. assembled hybrid vehicle model

A fan is mounted on the front end and connected to the rechargeable battery to harvest wind energy.

A microphone and an amplifying circuit are used to catch the ambient noise. The incoming noise is very low, thus an amplifying circuit has been used. It consists of-

1. Electrolytic capacitor - $1000 \mathrm{uF} / 35$ Volts for smoothening of current.

2. Electrolytic capacitor $-1000 \mathrm{uf} / 10 \mathrm{~V}$

3. A ceramic capacitor, 10000 pf ; Four, $1 \mathrm{~K}$ resistors.

4. Preset

5. An op amp,741CP

6. Two p-n diodes.

A mechanical displacement setup is used to harvest energy due to shocks, bumps and connected to the dynamo. A remote, receiving circuit is used to control the movement manually. The circuit consists of -

1. HT12E, encoder, 20 pin.

2. 4 Pin, TX20 transmitting chip working at $434 \mathrm{MHz}$

3. Four switches.

4. HT12D, decoder for decoding the signal from the transmitting chip.

5. 8952 microcontroller connected to four relays acting like a switch, connected to motors.

6. Two, 30 pf ceramic capacitors.

7. Two Electrolytic capacitors, $1000 \mathrm{uf} / 10 \mathrm{~V}$ and $100 \mathrm{uf} / 15 \mathrm{~V}$

8. LED, to signify what form of energy is being harvested that light up whenever a form of energy is being utilized.

9. A DC Motor.

\section{EXPERIMENTAL RESULT CALCULATION}

We tested the prototype in our campus and we got the following experimental results.

Initial Voltage $=4.09 \mathrm{~V}$

When the vehicle moves 12.2 meters, the voltage was recorded as $3.95 \mathrm{~V}$. Hence, Change in voltage $=0.14$ volts .

For every 10 meters the vehicle moves, battery consumption is 0.1102 volts.

\section{A. Solar Energy}

Placing the prototype with the solar panel in sunlight for about 32 minutes, the chargeable battery was recorded as $4.06 \mathrm{~V}$ change in voltage $=0.11$ volts

For 60 minutes,

Efficiency $=($ Final voltage/Initial voltage $) * 100$

$=(0.206 / 4.09) * 100=5.04 \%$

\section{B. Sound energy}

After use, the voltage drops to 3.98 volts

For a 5 minutes 32 seconds sound track, with moderate volume.

New voltage $=3.90$ volts

Change in voltage $=0.01$ volts

For one hour efficiency,

Efficiency $=(0.108 / 4.09) * 100=2.651 \%$

\section{Energy from suspension}

For 37 shocks with the rack and pinion arrangement, change in voltage $=3.979-3.972=0.007$ volts

For 100 shocks, the prototype moves 5.80 meter

Efficiency $=(0.0189 / 4.09) * 100=0.50 \%$

\section{Wind energy}

Voltage change for 100 rotations $=4.02-4.01=0.01006$ volts

Efficiency for 100 rotations $=(0.106 / 4.09) * 100=2.5 \%$

The bar graph shown in figure 7 gives us an experimentally calculated comparative graph of various forms of energy as discussed in the paper.

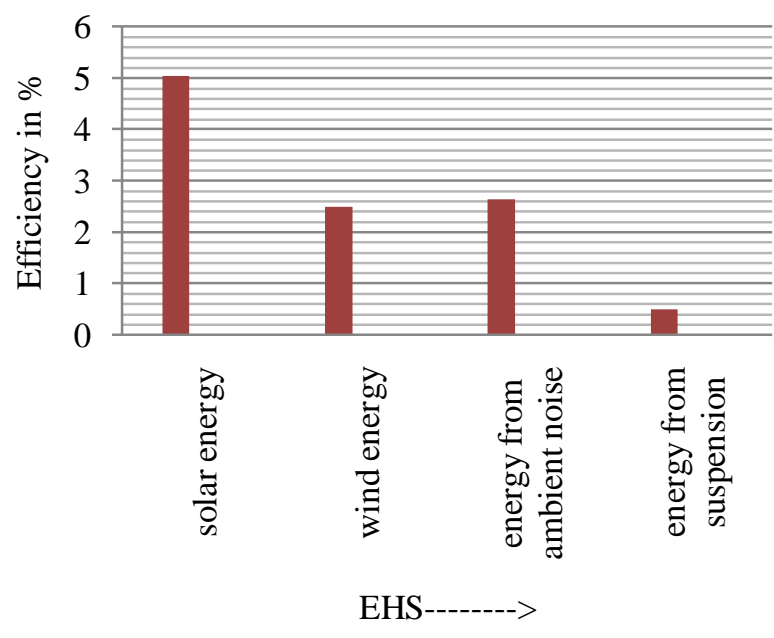

Figure 7. EHS Efficiency Graph 


\section{CONCLUSION}

This paper included an application of energy harvesting system in automobiles. These are renewable source of energy and the time when non-renewable sources are depleting; these sources are a blessing to human kind. They have various other advantages also like emission free environment, which in turn will support global warning issue as well.

In this paper we specifically discussed the use of solar, wind, suspension and ambient noise harvesting system for automobiles. We the help of prototype we found that these systems can significantly improve the system efficiency by charging the battery in scarcity of fuel in emergency conditions.

\section{REFERENCE}

[1]. Ashok Upadhyay, Arnab Chowdhury, "Solar Energy Fundamentals and Challenges in Indian restructured power sector ", International Journal of Scientific and Research Publications, Volume 4, Issue 10, pp 1-13, October 2014

[2]. M. Garg, D. Gera, A. Bansal and A. Kumar, "Generation of electrical energy from sound energy," International Conference on Signal Processing and Communication (ICSC), 2015, Noida, 2015, pp. 410-412. doi: 10.1109/ICSPCom.2015.7150687

[3]. http://www.osti.gov/scitech/servlets/purl/836856/

[4]. http://scienceline.ucsb.edu/getkey.php?key=3676

[5]. https://en.wikipedia.org/wiki/Pressure 